\title{
DNA damage response and DNA repair - dog as a model?
}

Nicole Grosse ${ }^{1,2}$, Barbara van Loon ${ }^{2 \dagger}$ and Carla Rohrer Bley ${ }^{1 * \dagger}$

\begin{abstract}
Background: Companion animals like dogs frequently develop tumors with age and similarly to human malignancies, display interpatient tumoral heterogeneity. Tumors are frequently characterized with regard to their mutation spectra, changes in gene expression or protein levels. Among others, these changes affect proteins involved in the DNA damage response (DDR), which served as a basis for the development of numerous clinically relevant cancer therapies. Even though the effects of different DNA damaging agents, as well as DDR kinetics, have been well characterized in mammalian cells in vitro, very little is so far known about the kinetics of DDR in tumor and normal tissues in vivo.
\end{abstract}

Discussion: Due to (i) the similarities between human and canine genomes, (ii) the course of spontaneous tumor development, as well as (iii) common exposure to environmental agents, canine tumors are potentially an excellent model to study DDR in vivo. This is further supported by the fact that dogs show approximately the same rate of tumor development with age as humans. Though similarities between human and dog osteosarcoma, as well as mammary tumors have been well established, only few studies using canine tumor samples addressed the importance of affected DDR pathways in tumor progression, thus leaving many questions unanswered.

Summary: Studies in humans showed that misregulated DDR pathways play an important role during tumor development, as well as in treatment response. Since dogs are proposed to be a good tumor model in many aspects of cancer research, we herein critically investigate the current knowledge of canine DDR and discuss (i) its future potential for studies on the in vivo level, as well as (ii) its possible translation to veterinary and human medicine.

Keywords: Canine and human tumors, DNA damage response, DNA repair

\section{Background}

Mutations in important driver genes, arising from various defects in the DNA damage response (DDR) pathways, can influence the tumor response to treatment. Hence, affected DDR pathways were a basis for the development of numerous clinically relevant cancer therapies. The effects of different DNA damaging agents, as well as DDR kinetics have been well characterized in mammalian cells in vitro. However, very little is known about the amount of actual DNA damage and the kinetics of DDR in tumors, as well as normal tissues in vivo under antineoplastic treatment.

\footnotetext{
* Correspondence: crohrer@vetclinics.uzh.ch

${ }^{\dagger}$ Equal contributors

'Division of Radiation Oncology, Vetsuisse Faculty, University of Zurich, Winterthurerstrasse 260, 8057 Zurich, Switzerland

Full list of author information is available at the end of the article
}

Only few studies utilized individual patient material, and initial DNA damage detection in patient tumor cells was rarely performed. Use of lymphocytes irradiated outside of the patient (ex corpora) [1,2] revealed individual patient heterogeneity and displayed more background DNA damage in cancer patients vs. healthy individuals $[3,4]$. Lymphocytes from human head and neck squamous cell carcinoma (HNSCC) patients irradiated ex corpora need more time to repair DNA double strand breaks (dsbs) than lymphocytes from healthy donors [5] and greater residual DNA damage was detected with the single cell gel electrophoresis (comet) assay in these patients $[1,2]$.

Several studies show that addressing DDR in vivo can lead to novel and clinically relevant insights. A non-invasive

\section{Biomed Central}

(c) 2014 Grosse et al.; licensee BioMed Central Ltd. This is an Open Access article distributed under the terms of the Creative Commons Attribution License (http://creativecommons.org/licenses/by/2.0), which permits unrestricted use, distribution, and reproduction in any medium, provided the original work is properly credited. 
approach in mouse xenograft tumors revealed a second wave of dsbs, marked by formation of phosphorylated histone variant $\mathrm{H} 2 \mathrm{AX}(\gamma \mathrm{H} 2 \mathrm{AX})$ foci, occurring 2 days after the initial wave [6]. The cause of this second, unexpected wave of dsbs is still unknown, with suspected causes of radiation induced genetics instability and apoptosis [6]. DDR studies in ex vivo cultures from normal human prostate tissue treated with ionizing radiation (IR) and cytotoxic agents resulted in different responses of basal versus luminal epithelial cells. The latter lacked $\gamma \mathrm{H} 2 \mathrm{AX}$ foci formation completely, despite normal 53BP1 foci formation [7]. Recently, some emphasis has been put on in vivo DDR studies in patients: (i) Base excision- and nucleotide excision repair (BER/NER) measurements in human colorectal biopsies (neoplastic and adjacent normal tissue), revealed patient- but not tissue-specific repair activity [8]. (ii) A study using normal epithelium of human breast cancer patients concludes that S/G2 cell cycle arrest during the course of radiation therapy (RT) leads to greater use of homologous recombination (HR) [9]. (iii) Analysis of HR defects in sporadic human breast cancer patients showed low RAD51 scores being a strong predictive marker of pathologic complete response to chemotherapy [10]. Taken together, these studies suggest that using DDR activity/proficiency as an in vivo readout could lead to a more effective and appropriate treatment of individuals.

Spontaneous tumors in companion animals like dogs have been described to offer a unique opportunity as a model for human cancer biology and translational clinical research [11]. In contrast to many murine tumor xenograft studies, canine tumors develop naturally and grow over long periods of time in the setting of an intact immune system. Human and canine tumors share many similarities, such as inter-patient tumoral heterogeneity, high incidence with age, similar biological behavior concerning development of resistance and metastasis, and comparable responses to antineoplastic agents. Furthermore, several studies indicated that factors of the DDR pathways also affect both disease development and treatment response in dogs [12-14]. As the evolution of most cancers in dogs is shorter than that of humans, conclusions from clinical studies can be drawn faster. Together with the high amount of dog owners willing to participate in clinical studies ([11,15] own experience), the dog could serve as a model to explore the importance of DDR and especially repair kinetics after antineoplastic treatment in vivo, thus offering opportunities for both human and animal healthcare. However, so far very little is known about DNA repair mechanisms and DDR in the canine background. Herein, we will critically investigate the current knowledge of canine DDR and discuss its potential to provide a basis as a model for DDR in vivo.

\section{Discussion}

Animals spontaneously developing cancer within an intact immune system are proposed to provide an excellent opportunity to investigate various aspects of cancer $[16,17]$. As opposed to experimental animals, companion animals are genetically outbred and immunologically competent, thus forming cancers that are more similar to human ones in terms of patient size, cell kinetics and heterogeneity. Moreover, clients (owners) are often willing to participate in well-designed clinical trials. Dogs share physiological and metabolic characteristics for most organ systems and drugs with humans and are large enough for multiple sampling opportunities, diagnostic and treatment interventions. Over the last years, several consortia of comparative oncology collaborations have formed and are managed under the National Institutes of Health (NIH)-National Cancer institute's Comparative Oncology Program (NCI-COP) in order to advance the study of comparative tumor biology and clinical investigations. The yearly cancer mortality rate for $\operatorname{dogs}<10$ years (deaths due to cancer per 10,000 dog-years-at-risk in Swedish dogs $<10$ years) is high with $50 \%$ in over 350,000 insured Swedish dogs and varies between breeds [18]. Over 1 million of pet dogs are diagnosed annually and managed with cancer in the United States [16], and these patients can often be entered in clinical trials when conventional treatments do not meet the goals of the veterinary oncologist. Features of certain canine cancers are already well characterized and show similarities with the human situation $[17,19]$. In the following sections we critically discuss, if - based on the current knowledge - the dog can be proposed as a model to study DDR in vivo, as well as point at missing links in this regard.

\section{Are canine and human genomes similar enough to comparatively study DNA damage response and repair?}

The canine genome has been sequenced and is available for studies identifying and associating genetically caused diseases, which are of relevance for both animal and human health. Bioinformatic analyses determined that around $94 \%$ of the dog genome belongs to regions of conserved synteny between the dog, human, mouse and rat genomes [20]. The euchromatic part of the canine genome is only about $18 \%$ smaller than the human genome [21], but the human and dog genomes differ largely in the chromosome number (46 and 78, respectively). With respect to the common ancestor of eutherian mammals $(\mathrm{CAE}, 2 \mathrm{n}=42)$, their genome is substantially rearranged. However, mouse and rat genomes are also severely altered with respect to the CAE genome, as they are highly rearranged and have accumulated large numbers of nucleotide substitutions in neutral sites [22]. Nonetheless, the canine gene products seem to be more closely related to their human homologs than those of mice. This suggests potentially higher 
functional similarity between canine and human proteins, as well as indicates possibly better crossreactivity of human antibodies with canine proteins than with murine ones, especially with respect to DDR proteins ([23]; own observations). The antibody crossreactivity would be especially beneficial in case of functional studies. Humans and dogs share an ancestrally related pathogenic basis for cancer, with pathognomonic genetic changes being conserved in both species [24]. As an example, the $B C R-A B L$ fusion gene could be detected with fluorescence in situ hybridization (FISH) in canine chronic myelogenous leukemia (CML) and chronic monocytic leukemia, which is equivalent to the Philadelphia chromosome (with the $B C R-A B L$ fusion) in human CML showing equal genomic break sites $[24,25]$. Besides similarities in proteincoding regions, it is important to keep in mind that the slight differences in the total amount of canine and human genetic material could result in different levels and regulations of the micro (mi) RNAs, which are becoming increasingly relevant. Apart from genetic alterations of proteins, alterations in the miRNA coding regions were shown to affect the regulation of DNA repair $[26,27]$. Nevertheless, as it is well established that the canine gene products are very similar to the human ones, the functional read-outs of canine studies based on the protein-coding regions do exhibit a high potential to result in deeper understanding and more accurate predicting of the treatment-response. Involvement of proteomic screens could provide additional insight in this matter.

\section{Are alterations in DNA damage response genes relevant for the development of canine cancer?}

In transformed tumor initiating cells with continuously activated DDR, throughout mammalian species, deregulated cell cycle check points and apoptosis mechanisms often prevent an efficient halt of proliferation and cell death induction. Amount of evidence clearly demonstrates that the very similar misregulations occur in both humans and dogs, resulting in genomic instability and tumor progression. Abrogation of p53 function by mutational and non-mutational mechanisms is one of the most frequent tumor suppressor gene inactivations in humans and domestic animals, while p53 dysfunction and MDM2 (ubiquitin E3 ligase of p53) overexpression play a central role in cancer progression [28-31]. Similarly, p16 an important cell cycle regulator encoded by the gene CDKN2A (Cyclin-dependent kinase inhibitors 2A; also called multiple tumor suppressor 1 ) is often mutated in a variety of human as well as canine cancers [32-34]. Loss of nuclear p16 expression is a prognostic marker for human melanoma and readily described in canine malignant melanoma [32,35,36]. P21, a CDK inhibitor regulating cell cycle progression is frequently down-regulated in both human and canine tumors [37,38]. Consequently, the extent of genomic instability has been described to be equally comparable in certain canine and human tumor types, such as osteosarcoma and colorectal cancer $[39,40]$. Taken together present finding clearly indicate that alterations in DDR genes are relevant for development of canine cancer, however to shed more light on tumor-associated defects, further investigations of different canine tumor types with regard to their mutational status and in particular the functional effects of mutations are needed.

\section{Can DNA damage response be compared and transferred between the two species?}

Only little is known about the DDR in the normal canine background and its potential alterations in neoplastic tissues. Nevertheless, as discussed bellow, few available studies indicate major similarities between human and canine DDR pathways.

\section{DDR initiation}

Upon Minute virus of canines (MVC, an autonomous parvovirus) infection classical DDR is triggered in canine cells [23]. ATM activation leads to strong H2AX phosphorylation whereas ATR leads to RPA32 phosphorylation; both of which were also reported to take place in human cells [23]. The MRN complex, which initially recognizes DNA dsbs was additionally visualized. In summary, the ATM-Mre11 axis is induced at the MVC replication centers during infection. To our knowledge the MVC study is the very first example of several important DDR proteins being detected with human antibodies in canine cell lines. Thus suggesting high homology between the proteins of two species. Another study confirmed that the broadly used human antibody against $\gamma \mathrm{H} 2 \mathrm{AX}$ is applicable in canine cells as well [41]. Although the MVC study is the only investigation of DDR initiation in canine cells, it: (i) implies similarities between human and canine response and (ii) represents an important starting point for exploring the impact of other stressors on canine cells.

\section{DNA dsb repair}

The amount of data directly comparing dsb repair kinetics in human and canine cells is very limited. One study addressing the capacity of nuclear extracts to bind a linear DNA probe (mimicking a DNA dsb) [42] revealed that in comparison to human extracts, proteins from canine extracts bind with a much lower affinity to linear DNA (28-fold); proteins from hamster cell extracts exhibited further decreased affinity [42]. The mechanism underlying this discrepancy is however not understood yet. Recent comparison of the dsb repair kinetics by pulse field gel electrophoresis (PFGE) after etoposide treatment 
indicated that the activity of fast non-homologous end joining (NHEJ) repair is $25 \%$ lower in canine than human cells, whereas the slow HR pathway seems to be similar. Unfortunately, in this study the relative ratio of migrated to non-migrated DNA was not taken into account, although it differed significantly between the two species [43]. NHEJ reduction in canine background potentially indicates that DNA-PKcs, main kinase in this pathway, could be more important in the primate background. Indeed the intrinsic activity of this protein is 13-fold lower in canine than in human fibroblasts [44]. The draw back of this study however is that it utilized whole cell extracts, in which the overall amount and activity of DNA-PKCS could be influenced by interspecies differences in the amount of cytosolic proteins or other components. Another potential consequence of increased DNA-PKcs activity in human cells is that DNA-PKcs and its partner $\mathrm{Ku}$ could bind faster to the DNA break ends in this background. Consequently, the breaks would be protected faster and more often repaired via classical NHEJ in human cells. As DNA-PKcs also regulates the activity of backup-NHEJ pathways, these might be more active in canine cells with less detectable DNA-PKcs [45]. If NHEJ is less active in canine cells, then HR might be a preferred dsb repair pathway.

In addition to above described findings of Park et al. suggesting that HR could be equally active in both species [43], mutations in different HR components have been analyzed in tumor setting. As BRCA-mutations lead to a higher risk of developing certain types of cancers in humans, the expression levels of these genes were analyzed in dogs with mammary cancer. In canine mammary carcinomas, BRCA2 and RAD51 show similar regulations, which indicates similar functions (Figure 1). In adenoma vs. normal samples, BRCA2/1 and RAD51 expression was reduced. In more advanced adenocarcinomas, however, BRCA2 and RAD51 were overexpressed in about $50 \%$ of the cases. Overexpression was even more pronounced in lymph node metastases [46]. Experimental studies are ongoing to clarify if these changes are a direct response to altered genetic stability or if they spontaneously occur during tumor formation. In English Springer Spaniels with mammary tumors, BRCA1 and BRCA2 genes seem to be involved in the development of the tumor [19]. Furthermore, BRCA1 is possibly involved in the malignant behavior [47]. However, the results are sometimes conflicting and more cases have to be analyzed to draw firm and general conclusions.

Taken together limited amount of data does not allow drawing of strong conclusions about the similarities between dsb repair in humans and dogs. However, there are clear indications that certain pathways such as HR might have higher degree of similarity between the two species. This could be of particular interest in translational

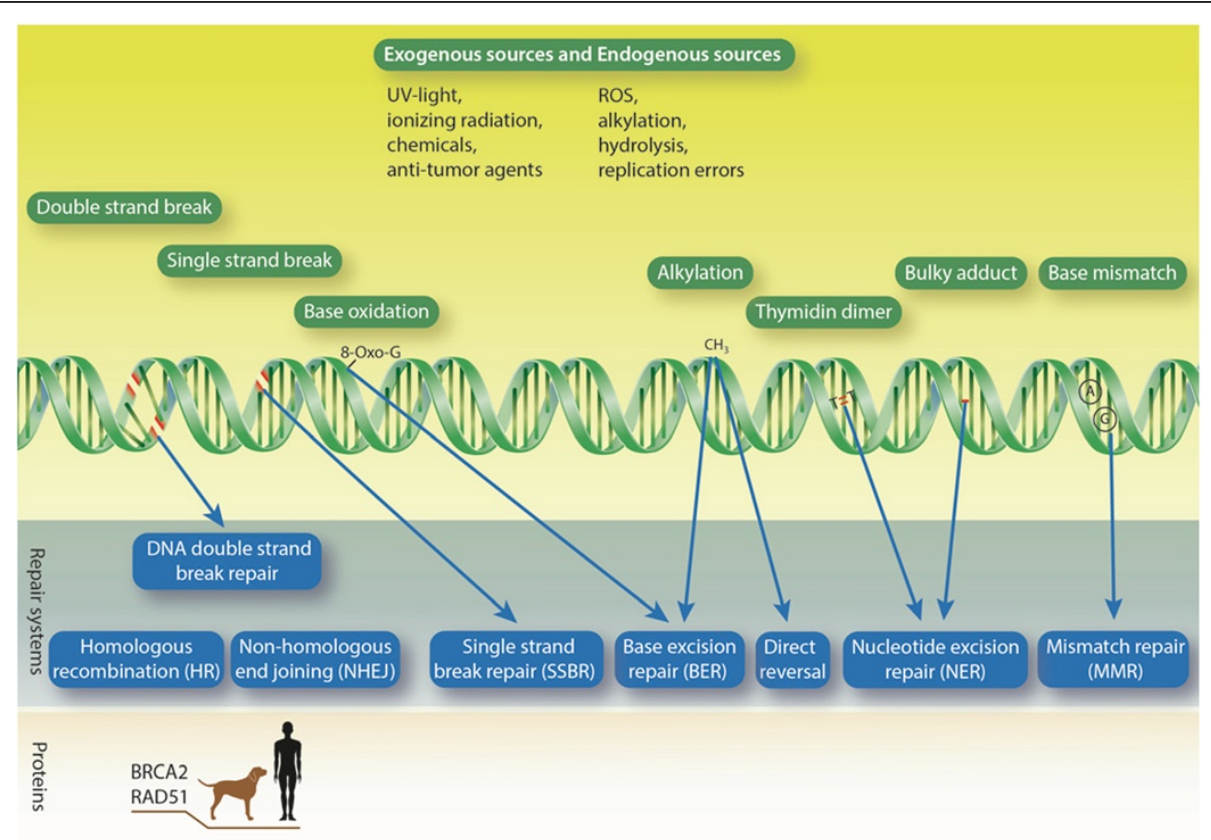

Figure 1 DNA damages and corresponding repair mechanisms. Various exogenous and endogenous DNA damaging agents attack the DNA on a daily basis. As a result many different types of DNA lesions are generated (green DNA strand with marked damage types (red or written) and green boxes with names of damage types). In order to survive, the cells harbor a set of repair pathways (blue boxes). Important players mutated or misregulated in both canine and human cancers are depicted in the lower part. 
research, particularly the one based on synthetic lethality. To fully understand the significance and extent of differences between human and canine NHEJ pathway future studies are needed such as, quantification of phosphorylated DNA-PKcs-foci, NHEJ assays using a pathwayspecific substrate, determination of DNA-PKcs protein levels with different antibodies and quantitative mass spectrometry. The activity and efficiency of HR in canine cells needs to be examined in further depth, among others by comparing human and canine Rad51 foci kinetics after the treatment with different genotoxic agents.

\section{Base excision repair and nucleotide excision repair}

Mechanisms like BER and NER have evolved to preserve the fidelity of the genomic material, which is continuously attacked by endogenous and exogenous stressors (Figure 1). The efficiency of the formerly mentioned repair pathways, especially BER, is thought to correlate with lifespan. Though dogs live shorter than humans (16.6 years vs. 90 years, respectively) [42], the BER capacity of canine and human embryonic fibroblasts under atmospheric oxygen tension (20\%) is not significantly different [43]. In contrast to BER, NER activity was shown to be significantly different between the two species $(25 \%$ lower in dogs) [43]. Performing the assay under physiological oxygen tension (3\%), BER activity was also lower in dog cells [43]. These two pathways could therefore vary in activity between the two different species. However, in the case of in vitro assays, the salt conditions and redox potentials influenced the reactions massively, which could explain observed repair differences between the species [48]. Furthermore, cellular growth conditions can influence the total BER protein expression [49], rendering direct inter-species comparisons difficult. Interestingly, the activity of DNA polymerase $\beta$, the key enzyme in filling a single nucleotide gap during BER, was increased in species with shorter lifespan [50]. Though these findings point at intriguing similarities and differences between human and canine excision pathways, as in case of dsb repair, extensive work is needed to understand to which extent DNA repair is comparable between the two species.

\section{In which tumors do we have sufficiently based potential to compare DNA damage repair? \\ Breast cancer}

Tumor gene expression studies of BRCA-mutations in malignant canine mammary tumors have shown varied results with under-expression of BRCA1 in malignant, as well as over-expression of BRCA2 in metastatic tumors $[46,47]$. As in women, germline mutations also showed a significantly increased risk of mammary cancer development in the examined breed of English Springer Spaniels $[18,19]$. BRCA2 and Rad51 expression were proposed as histologic criteria in canine breast cancer staging (Figure 1) [46]. While little is known about the DDR in canine mammary cancer, comparable BRCA2 and Rad51 misregulations, point towards a high possibility of similarly altered HR pathway in the two species.

\section{Prostate cancer}

Compared to men, the incidence of prostatic cancer in dog is low. However, the spontaneous development of the disease in dogs has awoken the interest to use dogs as a comparative model for prostate cancer [51]. The disease in dog behaves similarly to high-grade prostate cancer in men and - although the highly aggressive variant is rather rare in elderly men - the model character can be exploited for treatment strategies such as chemotherapy, vascular targeting, radiation therapy approaches and management of disseminated disease.

\section{Osteosarcoma}

Canine osteosarcoma has been shown in many studies to be a valuable comparative model, as it has many similarities on the genetic level, in clinical and biological behavior and in metastasis formation [52,53]. Case collection is more rapid, as osteosarcoma is much more common in dogs than in man. Common genetic and molecular alterations affect $\mathrm{p} 53$, retinoblastoma protein $(\mathrm{Rb}), \mathrm{c}-\mathrm{Met}, \mathrm{GH}$ and IGF-1 [52]. So far, little is known about DNA repair in canine osteosarcoma. In many DDR studies, the human osteosarcoma cell line U2OS was used and in further studies findings should be compared with canine osteosarcoma cell lines.

\section{Skin cancer}

Physical factors, such as cumulative exposure to DNA damaging agents, such as UV-radiation, and viral factors, such as papilloma-viruses, have been described as causative agents in canine cutaneous neoplasia. Canine skin tumors may also be induced directly through genetic mutations in factors such as p53 [54,55]. In two of the common malignant tumors of the skin, squamous cell carcinoma and melanoma genes and proteins regulating the cell cycle and cell death are affected. The p53 protein was shown to solely localize to the cytoplasm in many tumor cases [13]. P16 expression was significantly reduced [32]. Both proteins usually cause cell cycle arrest or delay, which provides the time for DNA repair or the induction of apoptosis in the case of heavily damaged cells. Therefore, misregulation of important tumor suppressor genes leads to genomic instability and progression of canine melanoma of the skin [32].

\section{Hematologic cancer}

Non-Hodgkin's lymphoma (NHL) represents the fifth leading cause of death due to cancer in humans and the 
high frequency of malignant lymphoma $(7-24 \%$ of all canine tumors) in dogs continues to increase as well. Chronic myelogenous leukemia (CML), sporadic Burkitt lymphoma (BL) and chronic lymphocytic leukemia/small lymphocytic lymphoma (CLL) are three well-characterized hematologic cancers that are morphologically similar in both species [24]. The common genetic mutations and altered oncogene or tumor suppressor gene expression, as well as signal transduction alterations (including $\mathrm{N}$-ras, p53, Rb, and p16 cyclin dependent kinase aberrations), have been reported to occur similarly in human lymphomas as well as in dogs $[14,56,57]$. In human chronic myelogenous leukemia (CML), an aberrant $B C R-A B L$ fusion transcript is the hallmark of the disease [24]. The aberration is seen in more than $90 \%$ of adult patients [58]. It was demonstrated that expression of BCR-ABL leads to the direct down-regulation of DNA-PKcs [59]. This proteasome-dependent degradation leads to a marked DNA repair deficiency and explains how secondary genetic alterations accumulate in CML. In five cases of canine CML, BCR-ABL translocations could be detected as well, affecting $11-34 \%$ of the cells [24]. Therefore, tumorigenesis of CML seems to be similar to the human malignancy. In the canine situation however, an additional down-regulation of DNA-PKcs still has to be verified.

In summary the five depicted tumor types are highly adequate models to translationally study tumor biology and treatment responses. We postulate that these tumors can also be used to study the DDR in vivo. In many of these tumors, cell cycle control proteins are altered, thus indicating increased genomic instability and DDR defects in spontaneously developing canine tumors.

\section{Summary}

In order to answer the question if studies in dogs have potential and perspective to serve as an in vivo model for DDR a positive outlook can be granted. Integrating spontaneous canine tumor models has several important advantages. Due to the high caseloads in veterinary clinics and shorter lifespan, studies can be performed quite fast. Cancers occurring in dogs and humans arise naturally with age, in the background of an intact immune system. They comprise many common features like histological appearance, tumor genetics, molecular targets, biological behavior and response to conventional therapies. Moreover, in many terms a canine model will even serve better than the murine one to study DDR and its defects in vivo, as in mice certain repair pathways seem to be less active in comparison to the human mechanisms. Therefore, mice have potentially a different emphasis and hierarchy of DNA repair pathways [43]. As described above, rather little is known about the DDR in canine cells and tissues. However, the antibody cross-reactivities of the human and canine proteins and the findings summarized in this article clearly show that the DDR of dog cells is potentially highly similar to human cells. In order to use canine tumor patients as models, the regulation and kinetics of the canine DDR will have to be studied more thoroughly at the biochemical and cellular level, by gene and mutational analyses as well as by global molecular pathway studies aiming to elucidate the similarities and differences to human cancers. In this way, the dog as our closest companion can help to better understand the DDR in vivo and to verify new treatment strategies on the DNA level in vivo.

\begin{abstract}
Abbreviations
ATM: Ataxia telangiectasia mutated; ATR: ATM and ataxia telangiectasia and Rad3-related protein; BER: Base excision repair; BRCA: Breast cancer protein; $B C R-A B L$ : Breakpoint cluster region-Abelson murine leukemia viral oncogene homolog; 53BP1: p53-binding protein 1; CAE: Common ancestor of eutherian; C-Met: MNNG HOS transforming gene; CDKN2A: Cyclin-dependent kinase inhibitors 2A; CIN: Chromosomal instability; CML: Chronic myelogenous leukemia; CLL: Chronic lymphocytic leukemia/small lymphocytic lymphoma; CRC: Colorectal cancer; DDR: DNA damage response; DNA: Deoxyribonucleic acid; DNA-PKcs: DNA-dependent protein kinase, catalytic subunit; dsb: Double strand break; FISH: Fluorescence in situ hybridization; GH: Growth hormone; GHR: Growth hormone receptor; H2AX: Histone variant 2AX; HER2: Human epidermal growth factor receptor 2; HNSCC: Head and neck squamous cell carcinoma; HR: Homologous recombination; IGF-1: Insulin-like growth factor 1; IR: Ionizing radiation; MDM2: Mouse double minute 2 homolog; MnSOD: Manganese superoxide dismutase; MRN: MRE11-RAD50-NBS1; MSI: Microsatellite instability; MVC: Minute virus of canines; Nbs1: Nijmegen breakage syndrome 1; NER: Nucleotide excision repair; NHEJ: Non-homologous end joining; NHL: Non-Hodgkin's lymphoma; NIH: National institutes of health; PFGE: Pulse field gel-electrophoresis; Rb: Retinoblastoma protein; RPA: Replication protein A; RT: Radiation therapy; SCID: Severe combined immunodeficiency; SSBR: Single strand break repair; UV light: Ultraviolet light.
\end{abstract}

\section{Competing interests}

The authors declare that they have no competing interests.

\section{Authors' contributions}

NG: Conception, design and writing. BvL: Conception, design, critical revision. CRB: Conception, design, writing and critical input. All authors read and approved the final manuscript.

\section{Acknowledgements}

We thank Jeanne Peter Zocher for the design of the illustration. Additionally we acknowledge the critical revision of the manuscript by $U$. Hübscher and F. Freimoser.

\section{Author details}

'Division of Radiation Oncology, Vetsuisse Faculty, University of Zurich, Winterthurerstrasse 260, 8057 Zurich, Switzerland. 'Institute for Veterinary Biochemistry and Molecular Biology, Vetsuisse Faculty, University of Zurich, Winterthurerstrasse 190, 8057 Zurich, Switzerland.

Received: 14 May 2013 Accepted: 13 March 2014

Published: 19 March 2014

\section{References}

1. Gamulin M, Garaj-Vrhovac V, Kopjar N: Evaluation of DNA damage in radiotherapy-treated cancer patients using the alkaline comet assay. Coll Antropol 2007, 31(3):837-845.

2. Nascimento PA, da Silva MA, Oliveira EM, Suzuki MF, Okazaki K: Evaluation of radioinduced damage and repair capacity in blood lymphocytes of breast cancer patients. Braz J Med Biol Res 2001, 34(2):165-176.

3. Palyvoda O, Polanska J, Wygoda A, Rzeszowska-Wolny J: DNA damage and repair in lymphocytes of normal individuals and cancer patients: studies 
by the comet assay and micronucleus tests. Acta Biochim Pol 2003, 50(1):181-190

4. Smith TR, Miller MS, Lohman KK, Case LD, Hu JJ: DNA damage and breast cancer risk. Carcinogenesis 2003, 24(5):883-889.

5. Walczak A, Rusin P, Dziki L, Zielinska-Blizniewska H, Olszewski J, Majsterek I: Evaluation of DNA double strand breaks repair efficiency in head and neck cancer. DNA and cell biology 2012, 31(3):298-305.

6. Li W, Li F, Huang Q, Shen J, Wolf F, He Y, Liu X, Hu YA, Bedford JS, Li CY: Quantitative, noninvasive imaging of radiation-induced DNA doublestrand breaks in vivo. Cancer Res 2011, 71(12):4130-4137.

7. Jaamaa S, Af Hallstrom TM, Sankila A, Rantanen V, Koistinen H, Stenman UH, Zhang Z, Yang Z, De Marzo AM, Taari K, Ruutu M, Andersson LC, Laiho M: DNA damage recognition via activated ATM and p53 pathway in nonproliferating human prostate tissue. Cancer Res 2010, 70(21):8630-8641.

8. Slyskova J, Korenkova V, Collins AR, Prochazka P, Vodickova L, Svec J, Lipska L, Levy M, Schneiderova M, Liska V, Holubec L, Kumar R, Soucek P, Naccarati A, Vodicka P: Functional, genetic, and epigenetic aspects of base and nucleotide excision repair in colorectal carcinomas. Clin Cancer Res 2012, 18(21):5878-5887.

9. Somaiah N, Yarnold J, Daley F, Pearson A, Gothard L, Rothkamm K, Helleday $\mathrm{T}$ : The relationship between homologous recombination repair and the sensitivity of human epidermis to the size of daily doses over a 5-week course of breast radiotherapy. Clin Cancer Res 2012, 18(19):5479-5488.

10. Graeser M, McCarthy A, Lord CJ, Savage K, Hills M, Salter J, Orr N, Parton M, Smith IE, Reis-Filho JS, Dowsett M, Ashworth A, Turner NC: A marker of homologous recombination predicts pathologic complete response to neoadjuvant chemotherapy in primary breast cancer. Clin Cancer Res: an Off J of the Am Assoc for Cancer Res 2010, 16(24):6159-6168.

11. Khanna C, Lindblad-Toh K, Vail D, London C, Bergman P, Barber L, Breen M, Kitchell B, McNeil E, Modiano JF, Niemi S, Comstock KE, Ostrander E, Westmoreland S, Withrow S: The dog as a cancer model. Nat Biotechnol 2006, 24(9):1065-1066.

12. Klopfleisch R, von Euler H, Sarli G, Pinho SS, Gartner F, Gruber AD: Molecular carcinogenesis of canine mammary tumors: news from an old disease. Vet Pathol 2011, 48(1):98-116.

13. Modiano JF, Ritt MG, Wojcieszyn J: The molecular basis of canine melanoma: pathogenesis and trends in diagnosis and therapy. J Vet Intern Med 1999, 13(3):163-174.

14. Veldhoen N, Stewart J, Brown R, Milner J: Mutations of the $\mathrm{p} 53$ gene in canine lymphoma and evidence for germ line p53 mutations in the dog. Oncogene 1998, 16(2):249-255.

15. Vail DM, MacEwen EG: Spontaneously occurring tumors of companion animals as models for human cancer. Cancer Invest 2000, 18(8):781-792.

16. Paoloni M, Khanna C: Translation of new cancer treatments from pet dogs to humans. Nat Rev Cancer 2008, 8(2):147-156.

17. Pinho SS, Carvalho S, Cabral J, Reis CA, Gartner F: Canine tumors: a spontaneous animal model of human carcinogenesis. Transl Res 2012, 159(3):165-172.

18. Egenvall A, Bonnett BN, Hedhammar A, Olson P: Mortality in over 350,000 insured Swedish dogs from 1995-2000: II. Breed-specific age and survival patterns and relative risk for causes of death. Acta Vet Scand 2005, 46(3):121-136.

19. Rivera $P$, Melin M, Biagi T, Fall T, Haggstrom J, Lindblad-Toh $K$, von Euler $H$ : Mammary tumor development in dogs is associated with BRCA1 and BRCA2. Cancer Res 2009, 69(22):8770-8774.

20. Lindblad-Toh K, Wade CM, Mikkelsen TS, Karlsson EK, Jaffe DB, Kamal M, Clamp M, Chang JL, Kulbokas EJ 3rd, Zody MC, Mauceli E, Xie X, Breen M, Wayne RK, Ostrander EA, Ponting CP, Galibert F, Smith DR, DeJong PJ, Kirkness E, Alvarez P, Biagi T, Brockman W, Butler J, Chin CW, Cook A, Cuff J, Daly MJ, DeCaprio D, Gnerre S, et al: Genome sequence, comparative analysis and haplotype structure of the domestic dog. Nature 2005, 438(7069):803-819.

21. Ostrander EA, Wayne RK: The canine genome. Genome Res 2005, 15(12):1706-1716.

22. Webber C, Ponting CP: Hotspots of mutation and breakage in dog and human chromosomes. Genome Res 2005, 15(12):1787-1797.

23. Luo Y, Chen AY, Qiu J: Bocavirus infection induces a DNA damage response that facilitates viral DNA replication and mediates cell death. J Virol 2011, 85(1):133-145.

24. Breen M, Modiano JF: Evolutionarily conserved cytogenetic changes in hematological malignancies of dogs and humans-man and his best friend share more than companionship. Chromosom Res 2008, 16(1):145-154

25. Cruz Cardona JA, Milner R, Alleman AR, Williams C, Vernau W, Breen M, Tompkins M: BCR-ABL translocation in a dog with chronic monocytic leukemia. Vet Clin Pathol 2011, 40(1):40-47.

26. Brunner S, Herndler-Brandstetter D, Arnold CR, Wiegers GJ, Villunger A, Hackl M, Grillari J, Moreno-Villanueva M, Burkle A, Grubeck-Loebenstein B: Upregulation of miR-24 is associated with a decreased DNA damage response upon etoposide treatment in highly differentiated CD8(+) T cells sensitizing them to apoptotic cell death. Aging cell 2012, 11(4):579-587.

27. Wu CW, Dong YJ, Liang QY, He XQ, Ng SS, Chan FK, Sung JJ, Yu J: MicroRNA-18a attenuates DNA damage repair through suppressing the expression of ataxia telangiectasia mutated in colorectal cancer. PLoS One 2013, 8(2):e57036.

28. Nasir L, Argyle DJ: Mutational analysis of the tumour suppressor gene p53 in lymphosarcoma in two bull mastiffs. Vet Rec 1999, 145(1):23-24

29. Nasir L, Argyle DJ, McFarlane ST, Reid SW: Nucleotide sequence of a highly conserved region of the canine p53 tumour suppressor gene. DNA Sea 1997, 8(1-2):83-86

30. Nasir L, Burr PD, McFarlane ST, Gault E, Thompson H, Argyle DJ: Cloning, sequence analysis and expression of the cDNAs encoding the canine and equine homologues of the mouse double minute 2 ( $\mathrm{mdm} 2$ ) proto-oncogene. Cancer Lett 2000, 152(1):9-13.

31. Nasir L, Rutteman GR, Reid SW, Schulze C, Argyle DJ: Analysis of p53 mutational events and MDM2 amplification in canine soft-tissue sarcomas. Cancer Lett 2001, 174(1):83-89.

32. Koenig A, Bianco SR, Fosmire S, Wojcieszyn J, Modiano JF: Expression and significance of p53, rb, p21/waf-1, p16/ink-4a, and PTEN tumor suppressors in canine melanoma. Vet Pathol 2002, 39(4):458-472

33. Lewis JS Jr: p16 Immunohistochemistry as a standalone test for risk stratification in oropharyngeal squamous cell carcinoma. Head Neck Pathol 2012, 6(Suppl 1):S75-S82.

34. von Knebel DM, Reuschenbach M, Schmidt D, Bergeron C: Biomarkers for cervical cancer screening: the role of p16(INK4a) to highlight transforming HPV infections. Expert Rev Proteomics 2012, 9(2):149-163.

35. Mihic-Probst D, Mnich CD, Oberholzer PA, Seifert B, Sasse B, Moch H, Dummer $R: p 16$ expression in primary malignant melanoma is associated with prognosis and lymph node status. Int J Cancer 2006, 118(9):2262-2268.

36. Straume O, Sviland L, Akslen LA: Loss of nuclear p16 protein expression correlates with increased tumor cell proliferation (Ki-67) and poor prognosis in patients with vertical growth phase melanoma. Clin Cancer Res 2000, 6(5):1845-1853.

37. Abbas T, Dutta A: p21 in cancer: intricate networks and multiple activities. Nat Rev Canc 2009, 9(6):400-414.

38. Castillo VA, Gallelli MF: Corticotroph adenoma in the dog: pathogenesis and new therapeutic possibilities. Res Vet Sci 2010, 88(1):26-32.

39. Maeda J, Yurkon CR, Fujisawa H, Kaneko M, Genet SC, Roybal EJ, Rota GW, Saffer ER, Rose BJ, Hanneman WH, Thamm DH, Kato TA: Genomic instability and telomere fusion of canine osteosarcoma cells. PLoS One 2012, 7(8):e43355.

40. Tang J, Le S, Sun L, Yan X, Zhang M, Macleod J, Leroy B, Northrup N, Ellis A, Yeatman TJ, Liang Y, Zwick ME, Zhao S: Copy number abnormalities in sporadic canine colorectal cancers. Genome Res 2010, 20(3):341-350.

41. Legare ME, Bush J, Ashley AK, Kato T, Hanneman WH: Cellular and phenotypic characterization of canine osteosarcoma cell lines. J Cancer Educ 2011, 2:262-270.

42. Lorenzini A, Johnson FB, Oliver A, Tresini M, Smith JS, Hdeib M, Sell C, Cristofalo VJ, Stamato TD: Significant correlation of species longevity with DNA double strand break recognition but not with telomere length. Mech Ageing Dev 2009, 130(11-12):784-792.

43. Park SH, Kang HJ, Kim HS, Kim MJ, Heo JI, Kim JH, Kho YJ, Kim SC, Kim J, Park JB, Lee JY: Higher DNA repair activity is related with longer replicative life span in mammalian embryonic fibroblast cells. Biogerontology 2011, 12(6):565-579.

44. Meek K, Kienker L, Dallas C, Wang W, Dark MJ, Venta PJ, Huie ML, Hirschhorn R, Bell T: SCID in Jack Russell terriers: a new animal model of DNA-PKcs deficiency. J Immunol 2001, 167(4):2142-2150.

45. Perrault $R$, Wang $H$, Wang $M$, Rosidi $B$, lliakis $G$ : Backup pathways of NHEJ are suppressed by DNA-PK. J Cell Biochem 2004, 92(4):781-794.

46. Klopfleisch R, Gruber AD: Increased expression of BRCA2 and RAD51 in lymph node metastases of canine mammary adenocarcinomas. Vet Pathol 2009, 46(3):416-422. 
47. Nieto A, Perez-Alenza MD, Del Castillo N, Tabanera E, Castano M, Pena L: BRCA1 expression in canine mammary dysplasias and tumours: relationship with prognostic variables. J Comp Pathol 2003, 128(4):260-268.

48. Osmond CB: Salt responses of carboxylation enzymes from species differing in salt tolerance. Plant Physiol 1972, 49(2):260-263.

49. Offer H, Zurer I, Banfalvi G, Reha'k M, Falcovitz A, Milyavsky M, Goldfinger N, Rotter V: p53 modulates base excision repair activity in a cell cycle-specific manner after genotoxic stress. Cancer Res 2001, 61(1):88-96.

50. Brown MF, Stuart JA: Correlation of mitochondrial superoxide dismutase and DNA polymerase beta in mammalian dermal fibroblasts with species maximal lifespan. Mech Ageing Dev 2007, 128(11-12):696-705.

51. Waters DJ, Shen S, Glickman LT, Cooley DM, Bostwick DG, Qian J, Combs GF $J$ r, Morris JS: Prostate cancer risk and DNA damage: translational significance of selenium supplementation in a canine model. Carcinogenesis 2005, 26(7):1256-1262.

52. Withrow SJ, Powers BE, Straw RC, Wilkins RM: Comparative aspects of osteosarcoma. Dog versus man. Clin Orthop Relat Res 1991, 270:159-168.

53. Withrow SJ, Wilkins RM: Cross talk from pets to people: translational osteosarcoma treatments. ILAR J 2010, 51(3):208-213.

54. Munday JS, Kiupel M: Papillomavirus-associated cutaneous neoplasia in mammals. Vet Pathol 2010, 47(2):254-264.

55. Nikula KJ, Benjamin SA, Angleton GM, Saunders WJ, Lee AC: Ultraviolet radiation, solar dermatosis, and cutaneous neoplasia in beagle dogs. Radiat Res 1992, 129(1):11-18

56. Sokolowska J, Cywinska A, Malicka E: p53 expression in canine lymphoma. J Vet Med 2005, 52(4):172-175.

57. Sueiro FA, Alessi AC, Vassallo J: Canine lymphomas: a morphological and immunohistochemical study of 55 cases, with observations on p53 immunoexpression. J Comp Pathol 2004, 131(2-3):207-213.

58. Kurzrock R, Kantarjian HM, Druker BJ, Talpaz M: Philadelphia chromosomepositive leukemias: from basic mechanisms to molecular therapeutics. Ann Intern Med 2003, 138(10):819-830.

59. Deutsch E, Dugray A, AbdulKarim B, Marangoni E, Maggiorella L, Vaganay S, M'Kacher R, Rasy SD, Eschwege F, Vainchenker W, Turhan AG, Bourhis J: BCR-ABL down-regulates the DNA repair protein DNA-PKcs. Blood 2001, 97(7):2084-2090

doi:10.1186/1471-2407-14-203

Cite this article as: Grosse et al:: DNA damage response and DNA repair - dog as a model? BMC Cancer 2014 14:203.

\section{Submit your next manuscript to BioMed Central and take full advantage of:}

- Convenient online submission

- Thorough peer review

- No space constraints or color figure charges

- Immediate publication on acceptance

- Inclusion in PubMed, CAS, Scopus and Google Scholar

- Research which is freely available for redistribution 